\title{
$\operatorname{CONF}-960268--10$
}

\section{Measurement of Process-Induced Strains in Composite Materials Using Embedded Fiber Optic Sensors}

\author{
Craig M. Lawrence and Drew V. Nelson \\ Department of Mechanical Engineering - Design Division \\ Stanford University \\ Jay R. Spingarn and Thomas E. Bennett \\ Sandia National Laboratories - Composites Laboratory \\ Livermore, CA 94551
}

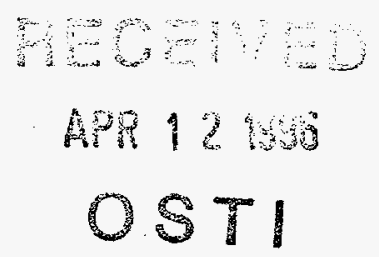

\begin{abstract}
This paper presents the results of experiments to measure the internal strains and temperatures that are generated in graphite/epoxy composite specimens during processing using embedded fiber optic strain sensors and thermocouples. Measurements of strain and temperature, combined with a computational model, offer the potential for nondestructive, real-time determination of residual stress in composites, and may be useful for process monitoring and control. Extrinsic Fabry-Perot interferometer, Bragg grating strain sensors, and thermocouples were embedded in graphite/epoxy composite laminates prior to cure. The specimens were cured in a press, and the internal strains and temperatures developed during processing were monitored and recorded. The results are compared with expected values, and limitations of the experimental technique are discussed.
\end{abstract}

Keywords: composite, residual stress, fiber optic sensor, Bragg grating, extrinsic Fabry-Perot Interferometer

\subsection{Introduction}

Fiber reinforced composite materials are used in many aerospace, civil, and industrial applications. To produce these materials, strong, stiff reinforcing fibers such as graphite or glass are embedded in a lightweight, compliant matrix such as epoxy to create a material which takes advantage of the beneficial mechanical and thermal properties of both constituents. Composite materials are often selected over traditional engineering materials because they may possess higher stiffness-to-weight and strength-to-weight ratios. Additionally, the mechanical and thermal properties of composites can be customized through the appropriate selection of constituent materials, geometry, and processing conditions. The increased use of composites in structural engineering applications has led to concern about the reliability of these materials. In particular, residual stress introduced during fabrication is cited as one of the most significant problems in the processing of composite structures [1]. These stresses can cause warping, or "spring-back," of the composite structure and can significantly degrade the strength of the material, resulting in cracking, reduced fracture toughness and fatigue strength, and delamination. The primary causes for residual stress in composites are thermal stresses due to the different coefficients of thermal expansion of the constituents, and curing stresses which result from chemical shrinkage of the matrix material during processing of polymer matrix composites.

Predicting residual stress in composites is difficult because of the large number of factors which contribute to the stress, including thermal, chemical, and viscoelastic effects, as well as moisture absorption. Experimental determination of residual stress in composites is also difficult. Often, the stresses of interest are located below the surface of the material, requiring the use of destructive techniques or non-standard measurement methods. To date, there is no universally accepted "best" method to measure residual stresses in composite materials. Methods developed for the measurement of residual stresses in metals have been extended and applied to composite materials. Most of the

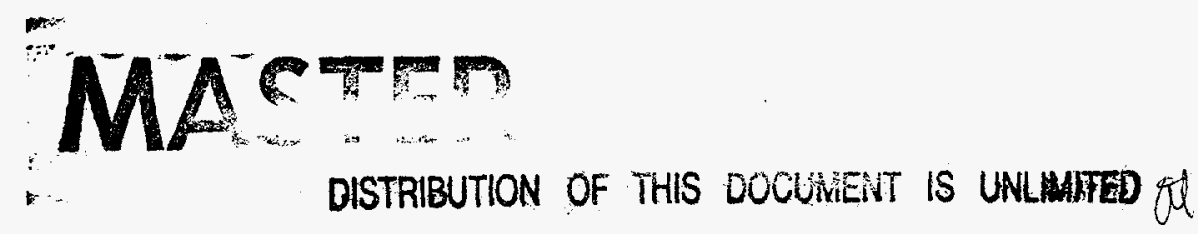


DISCLAMMER

Portions of this document may be illegible in electronic image products. Images are produced from the best available original document. 


\section{DISCLAIMER}

This report was prepared as an account of work sponsored by an agency of the United States Government. Neither the United States Government nor any agency thereof, nor any of their employees, make any warranty, express or implied, or assumes any legal liability or responsibility for the accuracy, completeness, or usefulness of any information, apparatus, product, or process disclosed, or represents that its use would not infringe privately owned rights. Reference herein to any specific commercial product, process, or service by trade name, trademark, manufacturer, or otherwise does not necessarily constitute or imply its endorsement, recommendation, or favoring by the United States Government or any agency thereof. The views and opinions of authors expressed herein do not necessarily state or reflect those of the United States Government or any agency thereof. 
methods used are destructive: material containing residual stress is removed from the specimen, and the resulting deformation is related to the magnitude and direction of the stress released. These methods have the obvious disadvantage that the part must be destroyed in order to obtain the measurement. This prohibits monitoring the development of residual stresses during processing, or the testing of a part in service. Non-destructive methods such as $\mathrm{x}-$ ray diffraction [2], neutron diffraction [3], photoelasticity [4], Raman spectroscopy [5], and optical fluorescence [6] have been extended to composite materials with varying degrees of success. Other methods, such as the embedded strain gage method [7], were developed specifically for composite materials.

In this study, measurements of the internal strains and temperatures developed in a composite laminate during processing were obtained using embedded fiber optic strain sensors and thermocouples. These experimental measurements can potentially be used as input conditions to a numerical process model which computes residual stresses. The fiber optic sensors could also be used to test methods of reducing residual stress during processing, and as sensing elements for smart structures currently proposed in aerospace; civil, and industrial applications [8].

\subsection{Fiber Optic Sensors}

The use of fiber optics for communications is well established. It is within relatively recent history, however, that the concept of using fiber optics for sensing has emerged. In 1978, Butter and Hocker [9] proposed a strain gage based on the change in optical path length in an optical fiber. Since that time, several other types of fiber optic sensors have been developed to measure strain, vibration, acceleration, pressure, and temperature [10]. One advantage that these sensors have over traditional strain gages is their compatibility with fiber reinforced composite materials. Their small size and cylindrical geometry make them well-suited for measurement of internal strain in these materials.

In this work, two types of fiber optic strain sensors were used: the extrinsic Fabry-Perot interferometer (FPI) and Bragg grating sensor. These will be described briefly in the next sections. More detailed descriptions can be found in the literature $[8,10]$.

\subsection{Extrinsic Fabry-Perot Interferometer}

Figure 1 presents a schematic of an extrinsic Fabry-Perot interferometer. Light from a source (laser, laser diode, white light source, etc.) is coupled into a lead-in fiber. The end of the lead-in fiber is attached to a small portion of hollow fiber, and a reflector (or reflecting fiber), is attached the opposite end of the hollow fiber. An air-gap is left between the end faces of the two fibers. A small portion of the light reaching the end of the lead-in fiber is reflected at the fiber end-face $\left(R_{1}\right)$. The rest of the light travels through the air gap, and is partially reflected at the reflector $\left(R_{2}\right)$. The light from the two reflections is transmitted back down the lead-in fiber to a detector. A fiber coupler can be used to separate the source light from the returning signal. Because the light from $\mathrm{R}_{2}$ will have travelled an additional distance through the air-gap $(=2 s)$, the two reflections will be out of phase and will interfere. As the length of the air gap changes due to axial strain of the hollow fiber, the relative phase between $R_{1}$ and $R_{2}$ will change. Several techniques exist to "demodulate" the return signal and compute strain.

The extrinsic FPI has the advantage that it is relatively insensitive to strains transverse to the axis of the fiber and to temperature changes. These sensors are suitable for "point" measurements since they can be manufactured with a small gage length $(<1 \mathrm{~cm})$. Disadvantages of this type of sensor are that they can be difficult to manufacture and calibrate, and the hollow-core fiber is usually larger than the lead-in fiber which can create difficulties for embedded applications. The FPI sensors and demodulation system used in these experiments were purchased from FISO Technologies in Quebec, Canada. 


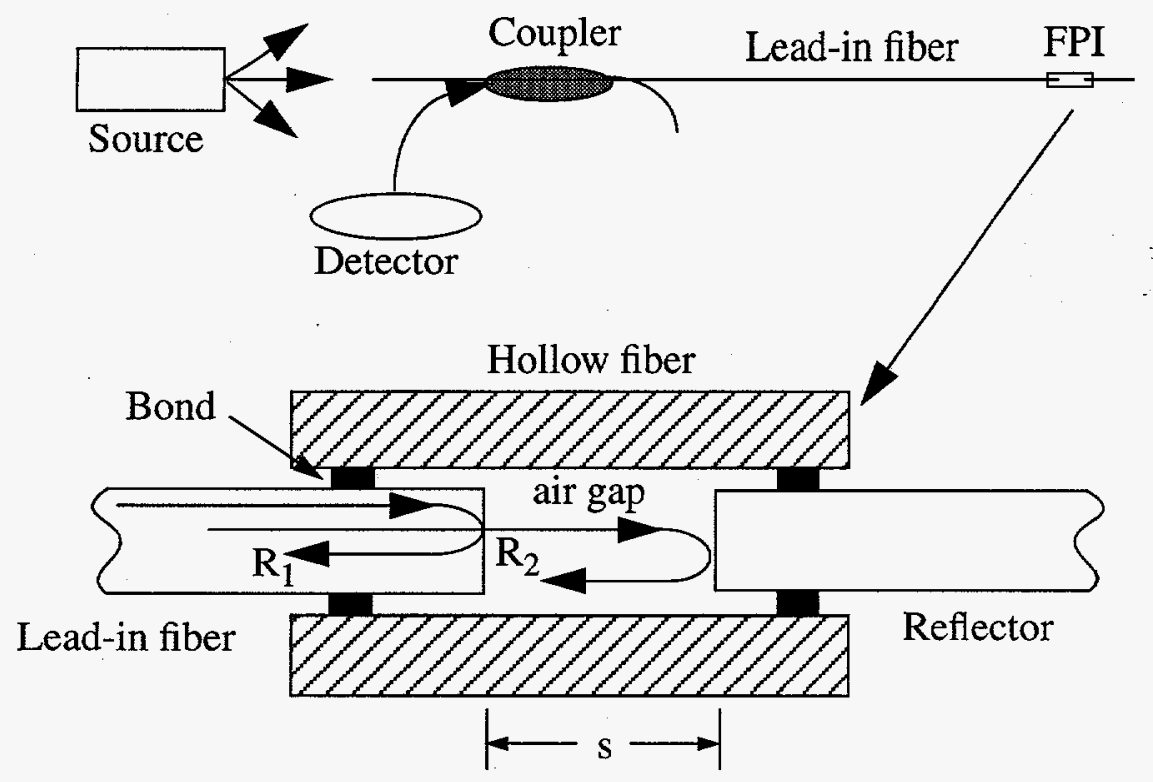

FIGURE 1. Extrinsic Fabry-Perot interferometer for the measurement of strain.

\subsection{Bragg Grating Sensor}

An intracore Bragg grating is a periodic modulation of the index of refraction of the core of a fiber formed by exposure to intense ultraviolet radiation [13]. Figure 2 presents a schematic of a Bragg grating sensor. When light from a broadband source is transmitted to the Bragg grating, the grating will reflect light with a peak wavelength at the Bragg wavelength, which is a function of the index of refraction of the core and the period of the index modulation. If the grating is subject to strain or a change in temperature, the Bragg wavelength will shift. This shift is fairly linear with temperature and axial strain. From the magnitude and direction of this wavelength shift, the value of the strain or temperature change can be determined. Several types of demodulation systems can be used to determine the wavelength shift including optical spectrum analyzers and tunable filters. One disadvantage of this sensor is that it is not possible to separate the effects of applied strain and temperature changes with a single grating. Bragg gratings are also sensitive to shear strains and strains transverse to the fiber axis because of the strain-optic, or photoelastic effect. Bragg gratings for this experiment were purchased from BraggTech International in Providence, RI, and a demodulation system was purchased from Research International in Woodinville, WA.

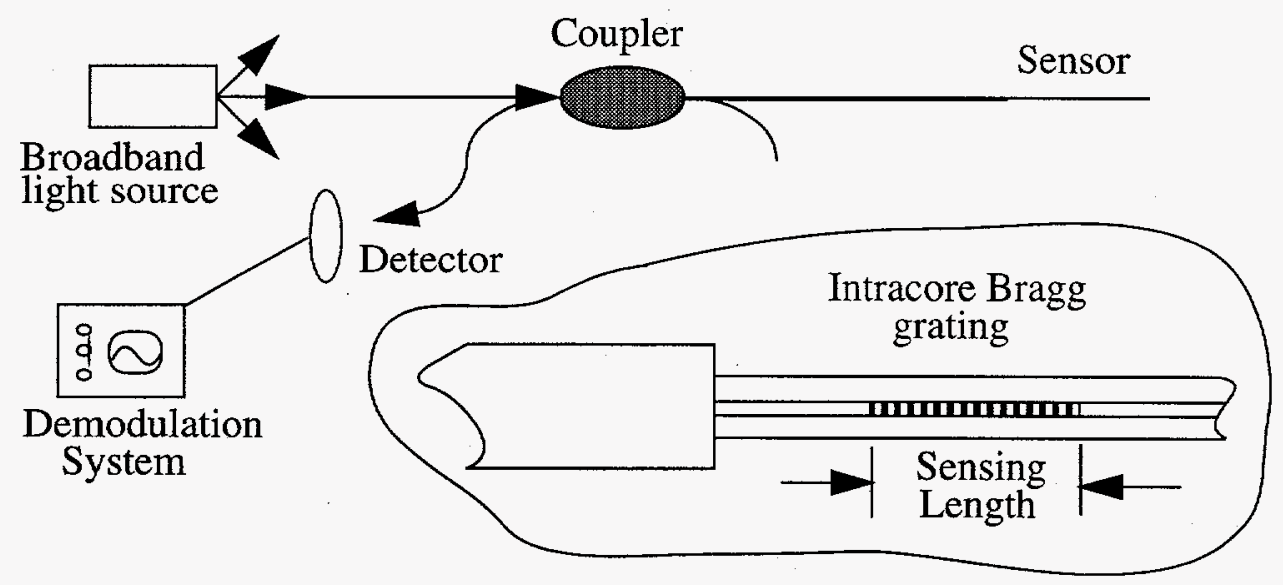

FIGURE 2. Bragg grating fiber optic sensor. 


\subsection{Experimental Procedure}

In this experiment, two extrinsic FPI strain sensors, one Bragg grating sensor, and one thermocouple were embedded in a $\left[0_{5} / 90_{5}\right]_{s}$ graphite/epoxy laminate as shown in Figure 3. The material used was HyE 6049U, a carbon fiber/ epoxy composite manufactured by Fiberite. Note that in all cases, the fiber optic sensors were aligned with the carbon reinforcing fibers and are placed between two plies of identical orientation. Experimental and analytical studies have shown that this is the optimal orientation to minimize the effect that the embedded optical fiber has on the surrounding host material [11]. Also, the sensing regions of the optical fibers were placed near the center of the laminate in order to avoid edge effects. The laminate was assembled by hand and cured in a hydraulic press according to the manufacturer's recommended cure cycle, shown in Figure 4. Twenty five hundred lbs of force was applied to the laminate during the cure, which is also in accordance with the manufacturer's recommendations.

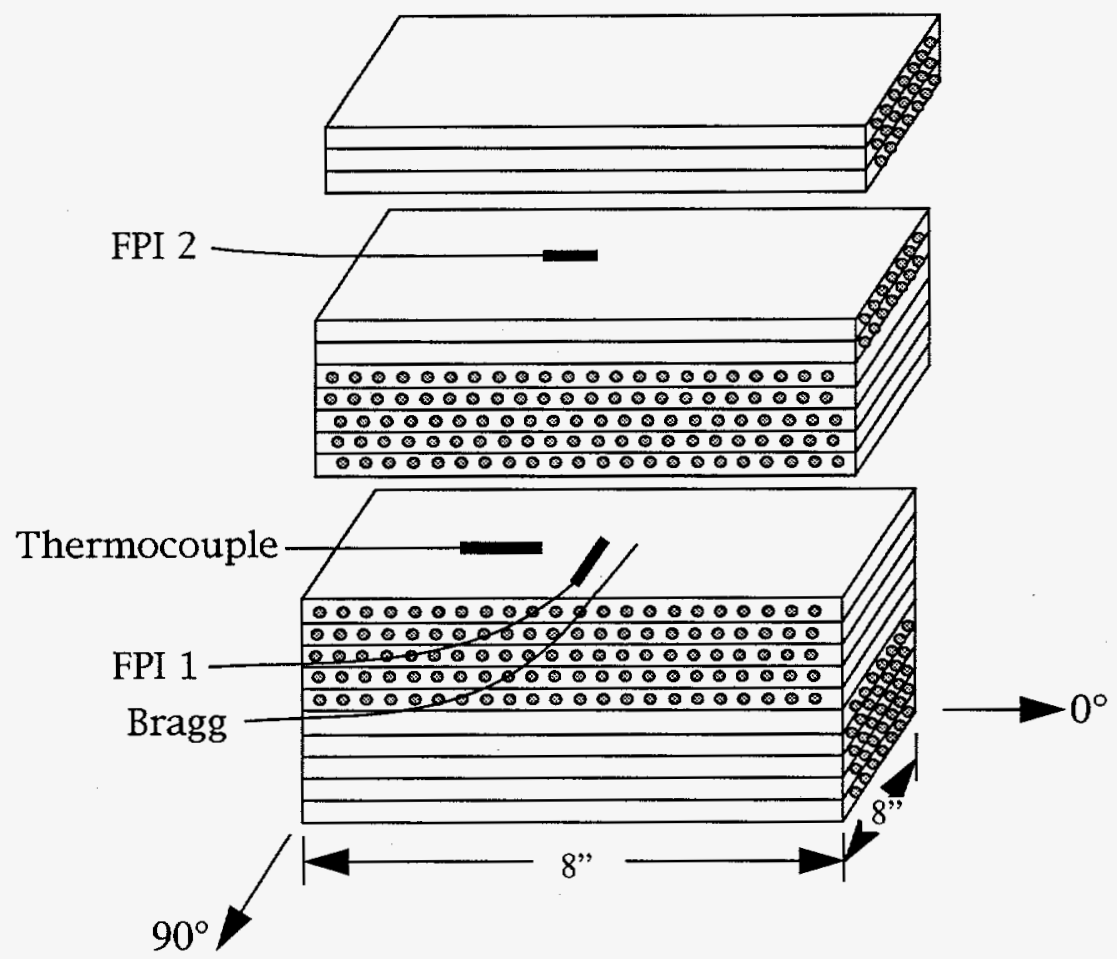

FIGURE 3. Schematic of test specimen

Several assumptions were made in these experiments. First, it was assumed that the temperature is constant throughout the composite specimen and that all of the sensors experience the same temperature, regardless of location in the laminate. It is believed that the specimen used was thin enough (approximately 0.125 ") so that heat transfer was rapid and temperature gradients were minimized. We have also assumed that the effects of strain and temperature in the Bragg Grating sensor can be separated using the temperature information provided by the thermocouple in the following manner:

$$
\varepsilon_{\text {actual }}=\varepsilon_{\text {measured }}-\varepsilon_{\text {thermal }}
$$

The thermal output (also called thermal apparent strain) is primarily due to the change index of refraction of the fiber core with temperature, and is given by:

$$
\varepsilon_{\text {thermal }}=C \cdot\left(T-T_{o}\right)
$$


Wher $T$ is the temperature of the Bragg grating, $T_{0}$ is room-temperature (taken arbitrarily as the "strain-free" temperature of the grating), and $\mathrm{C}$ is a constant relating the apparent strain measured by the Bragg grating to its change in temperature. For our system, $\mathrm{C}$ was experimentally determined to be $5.3 \mu \mathrm{in} / \mathrm{in} /{ }^{\circ} \mathrm{F}$, and the relation was linear up to the cure temperature of the composite. The output of the Bragg grating sensor was nulled at room temperature with no applied strain. From eqs. 1 and 2, the actual Bragg grating strain can be computed from the measured strain value and the measured temperature. One concern with this approach is that the Bragg sensors were calibrated at room temperature. A strain calibration factor, which relates the shift in Bragg wavelength to the applied axial strain, was determined by applying known axial strains to the fiber at room temperature and measuring the shift in Bragg wavelength. Inherent in this approach is the assumption that this strain calibration factor is independent of temperature. Additionally, the effects of transverse and shear strains on the Bragg grating are neglected in these experiments, although it is recognized that these may have a significant effect on sensor response [17]. The magnitude of such effects can be evaluated by comparing the Bragg response to an extrinsic FPI, which is not sensitive to transverse strains. Finally, it was assumed that the sensor and the surrounding material are perfectly bonded, and that all of the axial strain in the laminate is transferred to the sensor. Previous work by the authors and others indicates that fiber optic sensors remain well bonded in an epoxy host at low strain levels, at least up to $2000 \mu \mathrm{in} / \mathrm{in}[12,14]$.

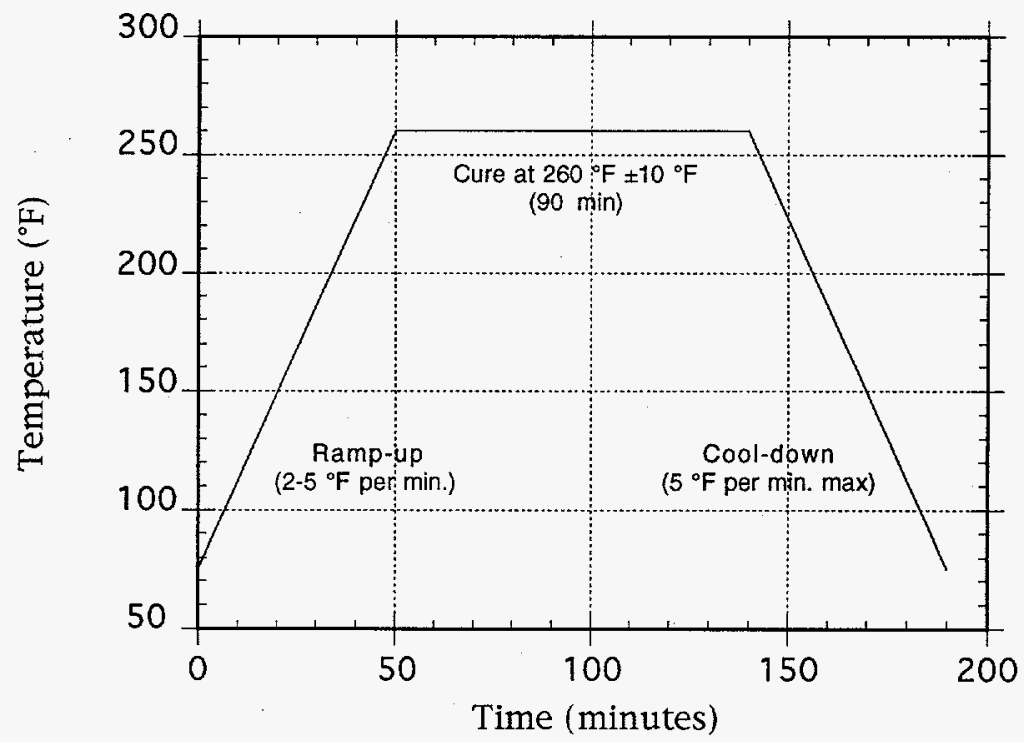

FIGURE 4. Manufacturer's recommended cure cycle for HyE $6049 \mathrm{U}$ composite.

\subsection{Results}

Figure 5 presents the thermocouple measurements during the cure cycle. Comparing this to Figure 4 , it appears that the manufacturer's recommended cure cycle was achieved. Figure 6 presents the measured strain during the cure cycle using the Bragg grating sensor $\left(\varepsilon_{\text {measured }}\right)$, which includes the effects of both axial strain and temperature. In order to separate these effects, eqs. 1 and 2 were used with the temperature data provided from the thermocouple. The resulting strain history is shown in Figure 7.

Three regions of interest can be identified from the data in Figure 7. First, during the ramp-up to the cure temperature, very little strain is observed. Some compressive strain is seen, and this may be caused by initial curing of the composite. However, this strain is reversed during the latter part of the ramp-up, possibly because of thermal expansion of the partially cured matrix. The strains observed during ramp-up were small and approached the resolution of the demodulation system used, which was approximately $15 \mu \mathrm{in} / \mathrm{in}$. 
In the second region, during the cure, compressive strains are built up, presumably due to the chemical shrinkage caused by cross-linking of the thermoset polymer matrix. These strains appear to build up slowly as the composite cures. Previous work by others [15] indicated that the chemical shrinkage during cure stops prior to complete curing of the composite. From the results presented in Figure 7, it is possible that chemical shrinkage is still occurring at the end of the manufacturer's recommended cure time, and that full cure has not been obtained. These results suggest the potential that an embedded fiber optic strain sensor can be used to determine the degree of cure in a composite during processing.

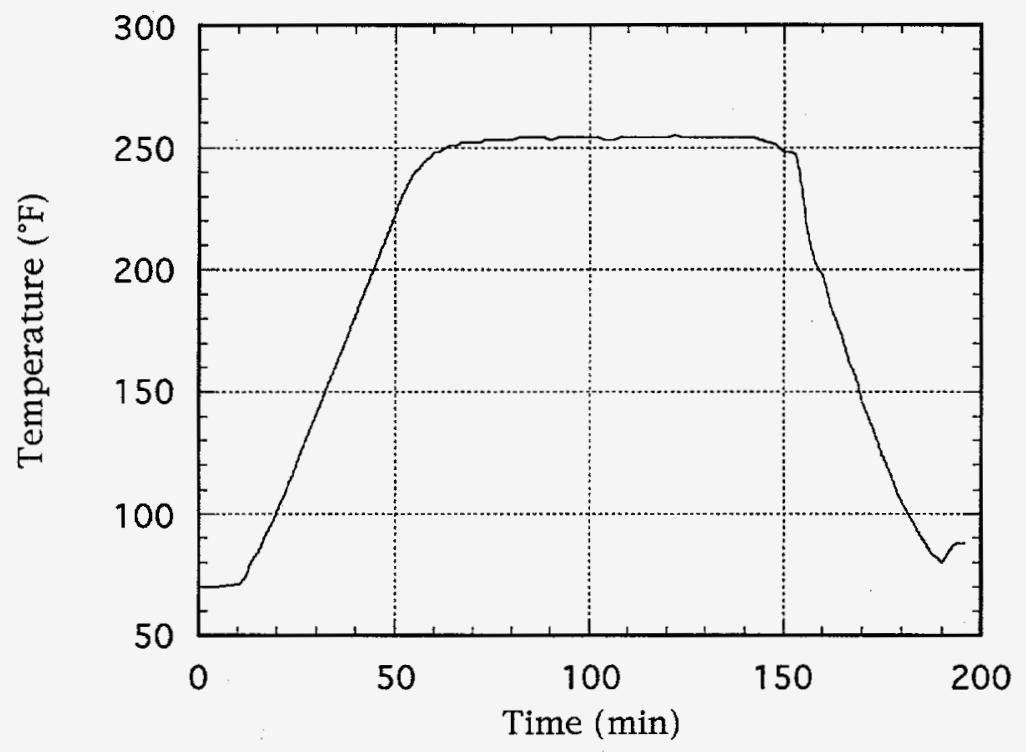

FIGURE 5. Temperature measured during cure with thermocouple.

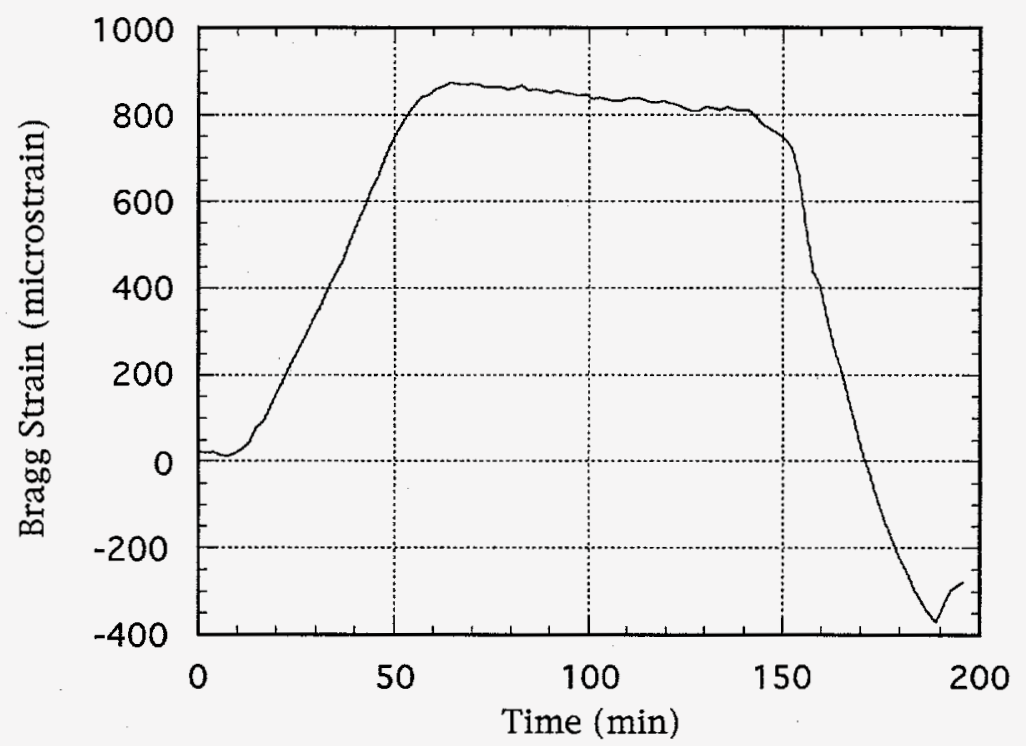

FIGURE 6. Output of Bragg grating sensor during cure. Note that the Bragg grating output includes the effects of both strain and temperature. The data have been smoothed. 


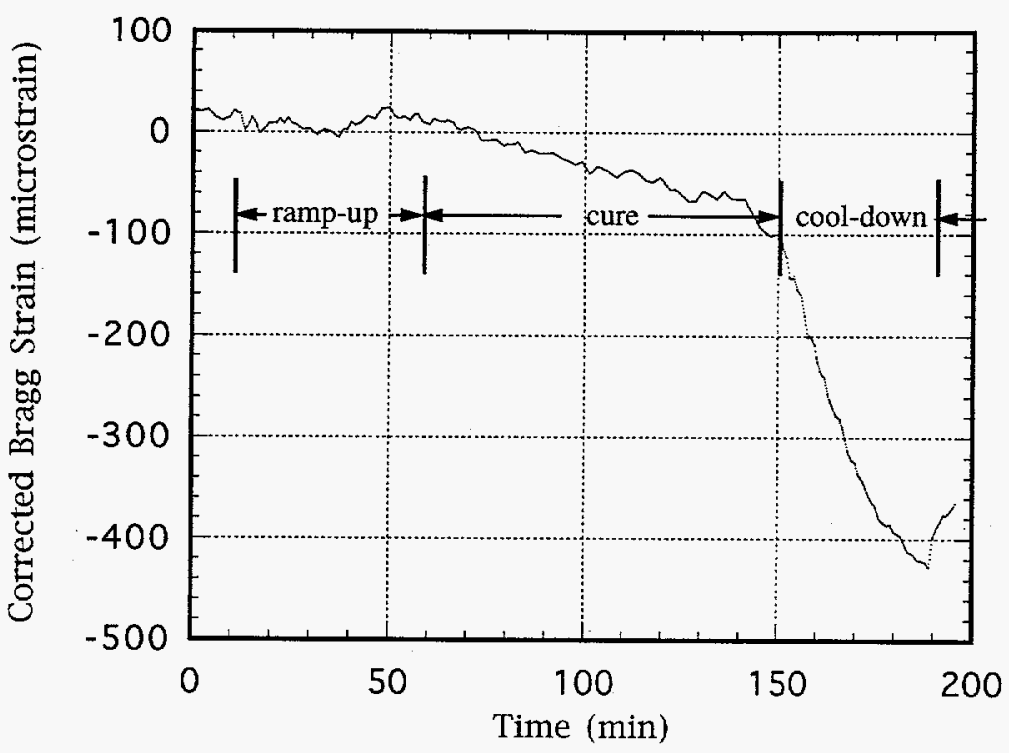

FIGURE 7. Output of Bragg grating sensor during cure corrected for thermal apparent strain. Correction factor used was 5.3 microstrain $/{ }^{\circ} \mathbf{F}$.

In the final cool-down phase, the strains due to thermal contraction of the laminate were observed. It is common to assume that during this phase, the composite has completely cured and solidified, and the strains induced during cool-down are purely due to thermal contraction. A plot of strain vs. temperature during the cool-down phase (Figure 8) indicates that the response of the laminate is fairly linear over this range, which is in agreement with previously reported results using resistive strain gages [16]. Deviations from linearity may be a result of viscoelastic effects or a variation of the coefficient of thermal expansion with temperature.

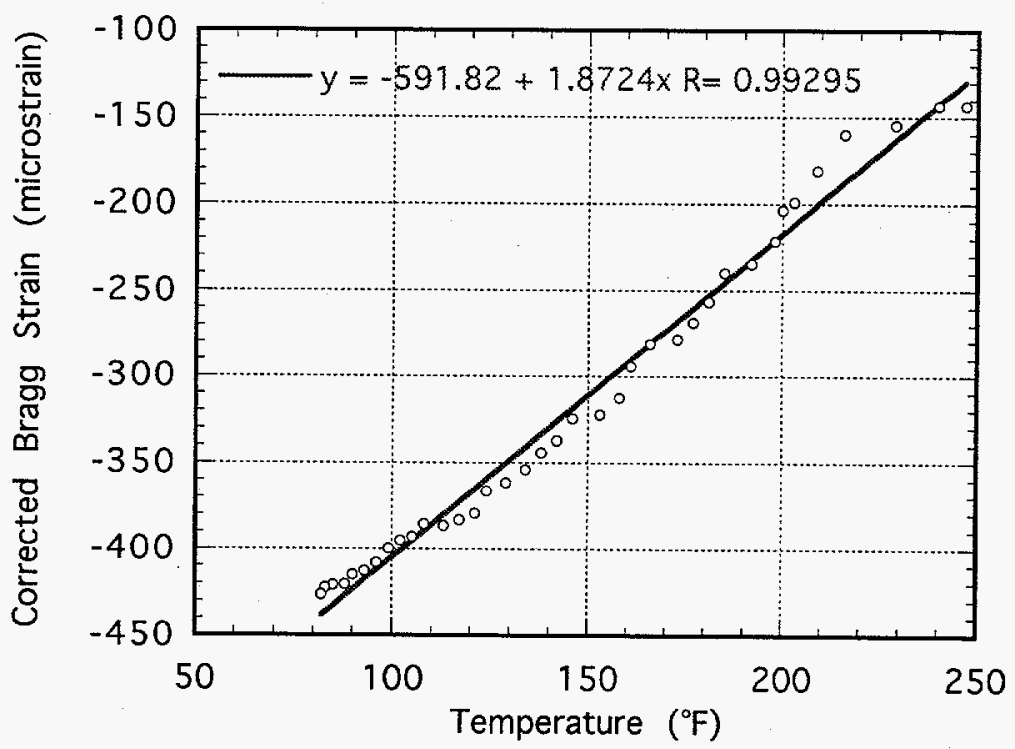

FIGURE 8. Graph of corrected strain versus temperature during the cool-down of the specimen. 
Figure 9 presents the strains measured with the two extrinsic FPI sensors. Several interesting features can be observed from this data. Sensor FPI 1, which was embedded adjacent to the Bragg grating sensor and in the same orientation, indicated a large spike of tensile strain during the cool-down phase of the cure. The Bragg grating sensor, which theoretically should be experiencing the same strain as FPI 1, did not indicate this spike. The cause of the spike is not known at this time, but it may be a result of improper bonding of the sensor to the host material. Because the laminate is symmetric $\left(\left[0_{5} / 90_{5}\right]_{\mathrm{S}}\right)$, we would expect FPI 1 and FPI 2 to indicate the same strain even though they are embedded in different plies and in orthogonal directions. Both sensors did indicate similar strain histories (except for the spike in FPI 1), and the differences could be explained by factors such as inadequate bonding to the epoxy matrix, slight misalignment of the sensors, local interactions with adjacent graphite reinforcing fibers, or thermal gradients through the thickness of the laminate. Neither of the FPI sensors indicated significant chemical compressive strains during the cure, while the Bragg grating indicated almost 100 microstrain of compressive strain during this period (Compare Figure 7 to Figure 9). It is possible that this difference may be caused by the sensitivity of the Bragg grating to transverse strains. As the surrounding matrix shrinks around the Bragg grating during cure, it will apply transverse strains to the sensor which can affect the output. In smart materials applications, this effect may have to be considered when the sensor is embedded in a region of unknown strain.

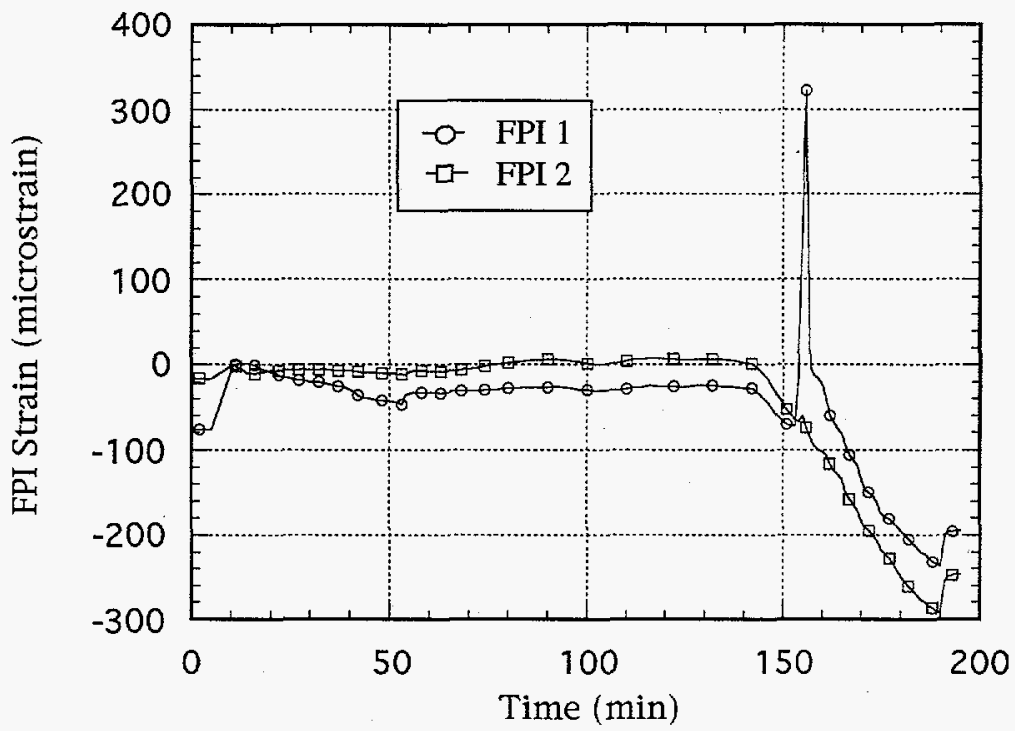

FIGURE 9. Process induced strains measured with the extrinsic Fabry-Perot interferometers.

\subsection{Conclusions}

Embedded fiber optic sensors were used to measure the process-induced strains during the cure of a graphite fiber/ epoxy composite laminate. These sensors demonstrated the ability to non-destructively measure chemical and thermal shrinkage strains internal to the composite part during the cure. Future research efforts will be aimed at using the data collected by embedded fiber optic strain sensors and thermocouples to compute the residual stresses developed during cure.

\subsection{Acknowledgments}

This work supported under DOE Contract \#DE-AC04-94AL85000 


\subsection{References}

1. White, S.R., and Hahn, H.T., "Process Modeling of Composite Materials: Residual Stress Development During Cure. Part I. Model Formulation," Journal of Composite Materials, Vol. 26, No. 16, 1992, pp. 2402-2422.

2. Fenn, R.H., Jones, A.M., and Wells, G.M., "X-Ray Diffraction Investigation of Triaxial Residual Stresses in Composite Materials," Journal of Composite Materials, Vol. 27, No. 14, 1993, pp. 1338-1351.

3. Kupperman, D.S., Majumdar, S., and Singh, J.P., "Neutron Diffraction NDE for Advanced Composites," Journal of Engineering Materials and Technology, Vol. 112, April 1990, pp. 198-201.

4. Nairn, J.A., and Zoller, P., "Matrix Solidification and the Resulting Residual Thermal Stresses in Composites," Journal of Material Science, Vol. 20, 1985, pp. 355-367.

5. Galiotis, G., Melanitis, N., Batchelder, D.N., Robinson, I.M., and Peacock, J.A., "Residual Strain Mapping in Carbon Fibre/PEEK Composites," Composites, Vol. 19, No. 4, July 1988, pp. 321-324.

6. Ma, Q., and Clarke, D.R., "Measurement of Residual Stresses in Sapphire Fiber Composites using Optical Fluorescence," Acta Metallurgical Material, Vol. 41, No. 6, 1993, pp. 1817-1823.

7. Daniel, I.M., Liber, T., and Chamis, C.C., "Measurement of Residual Strains in Boron-Epoxy and Glass-Epoxy Laminates," Composites Reliability, ASTM STP 580, American Society for Testing and Materials, 1975, p. 340-351.

8. Udd, E., Editor, Fiber Optic Smart Structures, Wiley, New York, 1995.

9. Butter, C.D. and Hocker, G.B., "Fiber optics strain gauge," Applied Optics, Vol. 17, No. 18, September 1978, pp. 2867-2869.

10. Udd, E., Editor, Fiber Optic Sensors: An Introduction for Engineers and Scientists, Wiley, New York, 1991.

11. Carman, G.P., and Sendeckyj, G.P, "Review of the mechanics of embedded optical sensors," Journal of Composites Technology \& Research, JCTRER, Vol. 17, No. 3, July 1995, pp. 183-193.

12. Miller, Mark S., et al. "Validation of axial strain transfer from a composite laminate to embedded optical fiber sensors," SPIE Vol. 1798, Fiber Optic Smart Structures and Skins V, 1992, pp. 19-29.

13. Morey, W.W., "Fiber optic grating technology," SPIE Vol. 2574, Pacific Northwest Fiber Optic Sensor Workshop, 1995, pp. 22-31.

14. Lawrence, C.M., and Nelson, D.V., "Validation of the absolute extrinsic Fabry-Perot interferometer for strain measurements," SPIE Vol. 2575, Pacific Northwest Fiber Optic Sensor Workshop, 1995, pp. 32-39.

15. White, S.R., and Hahn, H.T., "Process modeling of composite materials: residual stress development during cure. Part II. Experimental validation," Journal of Composite Materials, Vol. 26, No. 16, 1992, pp. 2423-2453.

16. Daniel, I.M., and Liber, T., "Effect of laminate construction on residual stresses in graphite/polyimide composites," Experimental Mechanics, Vol. 17, January 1977, pp. 21-25.

17. Udd, E., Nelson, D.V., Lawrence, C.M., Spingarn, J.R., Ferguson, B.A., "Three axis strain plus temperature fiber optic grating sensor," to be published in SPIE Vol. 2718.

\section{DISCLAIMER}

This report was prepared as an account of work sponsored by an agency of the United States Government. Neither the United States Government nor any agency thereof, nor any of their employees, makes any warranty, express or implied, or assumes any legal liability or responsibility for the accuracy, completeness, or usefulness of any information, apparatus, product, or process disclosed, or represents that its use would not infringe privately owned rights. Reference herein to any specific commercial product, process, or service by trade name, trademark, manufacturer, or otherwise does not necessarily constitute or imply its endorsement, recommanufacturer, or otherwise does not necessarily constitute or imply its endorser the views and opinions of authors expressed herein do not necessarily state or reflect those of the United States Government or any agency thereof. 